\title{
Searching for bioethical principles related to palliative care
}

\begin{abstract}
In a society where cure and disease prevention are health services main objectives, it is crucial to consider the caring and follow-up of terminally ill patients, in favor of palliative care promotion and dissemination. Thus, in the approach to palliative care, there is a complexity of physical, psychological and existential factors, and to ethical principles must be considered when providing care. This theme brings several paths to explore, becoming very important to clarify palliative care, to reflect about specific principles (avoiding confusion with concepts such as euthanasia, assisted suicide, dysthanasia), trying to find the point of balance among many existing conceptions when we talk in end-of-life issues. It is also important to emphasize the importance of the family's role and qualified health professionals, in a process of dignifying the patient, as autonomous, able to decide and for whom the finitude process that only makes sense with quality of life and relief from suffering, according to the beliefs and goals of life that holds.
\end{abstract}

Keywords: ethical aspects, palliative care, health professionals, family, quality at the end life
Volume 2 Issue | - 2018

\author{
Nunes Lucília \\ Department of Nursing, Health School Polytechnic Institute of \\ Setubal, Portugal
}
Correspondence: Lucília Nunes, Nursing Department, Health School Polytechnic Institute of Setubal, Portugal,

Email lucilia.nunes@ess.ips.pt

Received: January 29, 2018 | Published: February 16, 2018

\section{Introduction}

Our society has cultivated (or nurturing) a culture of focus in disease prevention and cure, pointing out that it is the main objective of the health services. In this way, it is vital to approach the final phase of life, namely palliative care, as a very important focus - health services, such as hospitals and primary health care, should dealing with and caring for terminally ill patients, which presents multiple demands, thus helping them to live with dignity and quality. The complexity of suffering and the combination of factors, such as physical, psychological and existential factors during the final phase of life, mean that we should approach with multidisciplinary teams, including health professionals with differentiated education and training but also the patient's family and the community.

In Portugal, the National Program for Palliative Care have defined palliation (the "relief patient suffering"), palliative actions ("Any therapeutic measure with no curative purpose, which aims at reducing the negative repercussions of the disease on the overall well-being of the patient" [1]) and palliative care ("Care provided to patients suffering from intense suffering due to incurable disease at an advanced and rapidly progressive stage, with the main objective of promoting, as much as possible and until the end, their well-being and quality of life." ).

So, palliative care is an organized response to the need to actively support and care for patients in the end of life. The family must be incorporated into these care, and it will be the object of care, during the illness and in mourning, so that in order to understand, accept and collaborate in the adjustments that the disease and the patient determine, they need to receive information, instruction and support. And we cannot underestimate the importance of a solid framework of ethical principles that we intend to present in this review.

The Quality of Death Index $2015^{2}$ evaluates 80 countries using 20 quantitative and qualitative indicators across five categories: the palliative and healthcare environment, human resources, the affordability of care, the quality of care and the level of community engagement. This Index point's one ranking, in which United Kingdom ranks first in the countries with the highest quality in the dying process, followed by Australia, New Zealand, Ireland, Belgium and Taiwan. What do these countries have in common? Among others, they have a strong and effectively implemented national palliative care policy framework, high levels of public spending on healthcare services, extensive palliative care training resources, wide availability of opioids analgesics and strong public awareness of palliative care.

\section{In search for bioethical principles in palliative care}

In a certain point of view, principles in the end-of-life should be the same of other stages of human life, at least for a person who can make their own choices and have a set of values, convictions and beliefs. However, "ethical issues in palliative care often arise because of concerns about how much and what kind of care make sense for someone with a limited life expectancy". ${ }^{3}$ Or, as been argued, death may come "very slowly and too late" for many. And the dying process became a bioethical issue, because of it complexity, specificity, the ultimate challenge about choosing how to live.

In a search, in databases, we write «end of life AND bioethical issues» in B-ON, with the criteria of peer reviewed, between 2013 and 2017; and we get 5,431 articles to read. And those articles include "Controversies surrounding continuous deep sedation at the end of life: the parliamentary and societal debates in France", ${ }^{4}$ or "Beyond cultural stereotyping: views on end-of-life decision making among religious and secular persons in the USA, Germany, and Israel", ${ }^{5,6}$ systematic reviews, cultural perspectives, clinical approaches.

If we search «end of life AND bioethical principles», with the same criteria, we found 3,941 articles. And there are surveys about "key opinion leaders on ethical resuscitation practices in 31 European Countries", 7 clinical approaches, search for consensus and practices, for example in "Do-not-resuscitate decisions" and a lot of us are 
asking a disturbing question: nowadays, How do we die?. ${ }^{9}$ So, if we search «palliative care» we find a lot of issues about end of life. And there is a huge, very high probability that we find the same set of principles in the end of life, and, specifically, in palliative care. And, if we look ahead, bioethical debate must address the dangers of several slippery slopes. And we are not thinking about the overuse of assisted suicide or euthanasia, or therapeutic futility, or continued overuse of treatments, about shortening life or incrementally longer life.

Because we are thinking about palliative care, we redesign the search - «bioethical principles AND palliative care», between 2013 and 2017, peer-reviewed, integral text. And we found 2.314 articles. It is a lot of papers, in five years. So, we change the positions: «palliative care AND bioethical principles»») - same criteria, and we found 715 articles in B-On and 7 articles in EBSCOhost.

\section{Discussion}

Seems to be consensual that the conduct we should have at the end of life situations should be directed towards the dignity of the human person and respect for their decisions about the death and dying process. And this statement seems clear but is quite vague, because respect for autonomy requires regard each person's values and viewpoints, listening to the person, assure they are capable of autonomous decisions. And, for that, proceed from self-determination in abstract, to the concrete elements of capacity to make decisions (the person know that are choices, is able to make them, understands the relevant information, appreciates the information significance in the context of its own situation and how that influences the options, balance the options, made a stable choice) and the decision to consent or decline the therapeutic project. Autonomy is not a static state of mind or a special skill - the person must have capacity and competence to decide about herself/himself. And we have to take in account the difference between an actual and a deferred consent or anticipated directive (advance directives).

The four-principle proposal of Beauchamp and Childress seems to be the most used framework - the principle of respect for autonomy is one of great relevance; the principle of beneficence that establishes a moral obligation to act for the benefit of the other; the principle of non-maleficence that indicates the health professional has a duty not to cause harm to the other and the principle of justice argues that all people have the right, and deserve consideration and respect, in obtaining equal assistance, but also in the struggle for the distribution of health resources and the maximum benefit for the community. Well, could be common but it clearly insufficient as framework-principles.

Thus, the main ethical distinction that exists in palliative care concerns the following and supporting the person in end-of-life process, in order to maintain their dignity and promote the relief of suffering and pain. It is almost annoying to find, everywhere, distinctions between palliative care and other situations or conditions in the end of life. If the disease is in its stage of evolution called "terminal", death is predictable in more or less short term; the interventions are aimed to alleviate symptoms (in particular, the pain) without acting on the cause; in this context, the aim of care is to preserve, not body integrity or health, but human dignity, which is the possibility for every human being, through his conscience, to act freely and self-determine. This affirms the value of life and of dealing with the process of dying as a normal process in the course of life. Do not delay or speed death. It is intended to provide relief from pain and other distressing symptoms. Psychological and spiritual aspects are integrated and provide a support system that helps the family in aspects that relate to the illness of their loved one and their own mourning.

If we are focused on palliative care, we must integrate principles that really matters in the end of life. Specially, if we take in account that bioethics is an ethical-oriented reflection focusing on scientific development, leads to the extent of the limits imposed on this progress. If the purpose of science is to improve the quality of life of people and society as a whole, some ethical limits must be equated with the infinite horizon of the appetite for scientific knowledge. It is clear we also have to reaffirm the difference between the technically possible and the ethically permissible. And is vital to reinforce the idea that human dignity is the true pillar from which other principles emerge and must be unequivocally present in all decisions and interventions. It is necessary to emphasize the communication and the autonomy of the person at the end of his life. Thinking about communication, I recall a phrase by Bernard Shaw, who stated that "All professions are conspiracies against the laity" but this can be much more distressing when there are technical problems in the language. Roughly, it means that it can be difficult to understand the scientific "mess" of the diagnostic and therapeutic areas. It also refers to cases where there are problems of clarity in the messages, which tend to produce confusion and therefore do not confer security. So, truth-telling in clear messages became very important, and we mark the special importance of truly share the information which will be used in making a good decision no matter it is difficult or need a special learning.

Also, vulnerability - the quality or state of being exposed to the possibility of being attacked or harmed, either physically or emotionally; the human fragility exposed to finitude and mortality requires a different notion of time and a effective compassion. It isn't a matter of pity or sympathy. Neither empathy, in the presumption to understand the place of ten other. Compassion involves allowing ourselves to be moved by suffering, in helpfulness acts. People talk about altruism but compassion is more about perceiving others' pain and distress and being motivated to relieve it. In palliative care, confidentiality as duty to respect the person privacy means the respect for privacy and inner and personal life. Finally, an individual care plan centered in the person, meaning, shared design of goals of care, agreement about what is to be done, based on excellent communication between the members of the team.

Several studies findings points out the inadequate or insufficient communication and, also, inadequate discussion (focused on goals and expectations, the fears and the degree of suffering) or poor pain and symptom management. And palliative care in most countries have the challenge to struggle against lack of time for quality communication, lack of competencies in palliative care, poor communication skills, little understanding about terminal sedation. And, also, with cultural and religious issues related to dying persons as well as the balance between the person in the end of life and the family or the loved ones. The palliative care objective is to provide the best possible quality of life for the terminally ill patient and his / her family until the moment of death, in a truly human way, respecting the limits of the dignity of the person.

\section{Conclusion}

To improve quality in the personal, individual dying process, we need to contribute for a society where death and dying process would be a matter of dialogue, avoiding concealment and denial; we need a better health literacy and education to death. And because palliative 
care supports the identity and values of the person, the conservation of dignity is a central principle. In the same way that each one of us gives different content to happiness, quality of life means different things for different people. And is not up to me to judge the quality of life of another human being. And it is important to take notice that palliative care adopts a holistic approach and each one is a singular one, shaped by its own biography.

Misconceptions about palliative care act as hurdling and, in the worst scenario, decrease the opportunity time for care provision-even if in the country a small amount of people could apply for palliative care. We need awareness about palliative care, an extremely important topic to discuss, as it promotes a dignified death for all patients who do not have other perspectives of treatment. However, there is still some lack of knowledge about the population in general, and it is therefore essential that health education be promoted, promoting disease prevention, promoting healing, and continuing unceasing pursuit of the most innovative treatments, but without neglecting palliative care, when nothing else is liable to do. Since death is the end we all have in common, and although it is sometimes a delicate issue and not everyone has the tools to deal with it, education about the issues that are inherent in palliative care, such as comfort, wellbeing and quality of life among so many others (yes, because it is possible to provide this to a terminally ill patient). It is also essential to understand the ethical issues that underlie.

\section{Acknowledgements}

None.

\section{Conflict of interest}

The author declares no conflict of interest.

\section{References}

1. DGH. National Program for Palliative Care. Directorate-general for health, Portugal: Springer; 2005. 6 p.

2. The Economist. The 2015 quality of death index. Ranking palliative care across the world. 2015.p. 1-86.

3. Ko DN, Perez-Cruz P, Blinderman CD. Ethical issues in palliative care. Prim Care. 2011;38(2):183-193.

4. John Hardwig. Going to meet death, Hastings Cent Rep. 2009;39(4):3745 .

5. Raus K, Chambaere K, Sterckx S. Controversies surrounding continuous deep sedation at the end of life: the parliamentary and societal debates in France. BMC Medical Ethics. 2016;17(1):36.

6. Schweda M, Schicktanz S, Raz A, et al. Beyond cultural stereotyping: views on end-of-life decision making among religious and secular persons in the USA, Germany, and Israel. BMC Medical Ethics. 2017;18(1):13.

7. Mentzelopoulos SD, Bossaert L, Raffay V, et al. Clinical paper: A survey of key opinion leaders on ethical resuscitation practices in 31 European Countries. Resuscitation. 2016;100:11-17.

8. Santonocito C, Ristagno G, Gullo A, et al. Consent/End of Life: Do-notresuscitate order: a view throughout the world. Journal of Critical Care. 2013;28(1):14-21.

9. Stabile B, Grant A. How do we die? Politics Life Sci. 2016;35(2):69-74. 